\title{
Leporine Experimental Organism Diagnosis
}

National Cancer Institute

\section{Source}

National Cancer Institute. Leporine Experimental Organism Diagnosis. NCI Thesaurus.

Code $C 134530$.

A condition that is relevant to either disease states or models of disease in rabbits. 